\title{
Effects of depression and pain severity on satisfaction in medical outpatients: Analysis of the Medical Outcomes Study
}

\author{
Matthew J. Bair, MD, MS; ${ }^{1-2 *}$ Kurt Kroenke, MD; $;^{1-2}$ Jason M. Sutherland, PhD; $^{1-2}$ Kimberly D. McCoy, MS; $^{1}$ \\ Hillary Harris, MS; ${ }^{3}$ Colleen A. McHorney, PhD $^{4}$ \\ ${ }^{1}$ Health Services Research and Development Center of Excellence on Implementing Evidence-Based Practice, Richard \\ L. Roudebush Department of Veterans Affairs Medical Center, Indianapolis, IN; ${ }^{2}$ Indiana University Center for Health \\ Services and Outcomes Research, Regenstrief Institute, Inc, Department of Medicine, Indiana University School of \\ Medicine, Indianapolis, IN; ${ }^{3}$ RTI International, Research Triangle Park, NC; ${ }^{4}$ Merck \& Company Inc, West Point, PA
}

\begin{abstract}
Patient satisfaction has been used as a healthcare quality indicator. We examined how depression and pain severity affected satisfaction in medical outpatients. Data from the Medical Outcomes Study were analyzed. The primary outcomes were seven satisfaction domains from the Patient Satisfaction Questionnaire. Depression was identified through a clinical interview, and pain was assessed with the 36-item Short Form Bodily Pain scale. We performed multivariate linear regression to predict satisfaction in outpatients with depression and pain. Minor and major depression were present in $23.4 \%$ and $15.0 \%$ of the sample, respectively. Pain was present in more than half the patients (50.6\%). Both minor and major depression as well as pain severity were strongly associated with lower satisfaction scores. Increased age and diagnosis of heart failure predicted higher satisfaction scores. Depression and pain have a substantial effect on patient satisfaction. Future studies should assess the reasons for dissatisfaction with care in patients with depression and pain.
\end{abstract}

Key words: ambulatory care, chronic disease, depression, healthcare quality indicator, Medical Outcomes Study, outpatients, pain, patient satisfaction, Patient Satisfaction Questionnaire, rehabilitation.

\section{INTRODUCTION}

Studies have reported widespread deficits in healthcare quality in the United States [1-2]. Spurred by these reports, researchers have developed numerous quality improvement strategies. Correspondingly, patient satisfaction ratings have been emphasized as indicators of healthcare quality and improvement efforts [3]. Patient satisfaction with healthcare has been shown to reflect clinical outcomes (e.g., treatment effectiveness) [4], healthrelated behaviors [5], and adherence to treatment [6]. For example, dissatisfied patients are less likely to adhere to treatment regimes or recommendations [7-8], more likely to initiate malpractice suits [9], and more likely to switch healthcare providers [10] or health plans [11].

Studies examining the correlates of patient satisfaction in patients with depression or pain have been few in number and the results conflicting. While at least one study found no association between affective disorders

Abbreviations: DIS = Diagnostic Interview Schedule, DSMIII = Diagnostic and Statistical Manual of Mental DisordersThird Edition, GEE = generalized estimating equation, MOS = Medical Outcomes Study, NIMH = National Institute of Mental Health, PSQ-III = Patient Satisfaction Questionnaire-Third Edition, SF-36 BP = 36-item Short Form Bodily Pain (scale), VA = Department of Veterans Affairs.

* Address all correspondence to Matthew J. Bair, MD, MS; Richard L. Roudebush VA Medical Center, Center of Excellence on Implementing Evidence-Based Practice, 11-H, 1481 West 10th Street, Indianapolis, IN 46202; 317-5540000, ext 5766; fax: 317-554-0114. Email: mbair@iupui.edu DOI: 10.1682/JRRD.2006.06.0061 
and patient satisfaction [12], others show that depression predicts dissatisfaction with care [13-14]. Furthermore, Meredith et al. showed that patient dissatisfaction was associated with poorer quality of medication management for depression [15]. The literature on patient satisfaction in patients with pain has been inconsistent as well. While dissatisfaction was commonly found in women with chronic pelvic pain [16], several researchers have reported high satisfaction ratings despite significant levels of pain [17-19]. This interesting phenomena has been termed the "pain paradox" [20], contradicting the expectation that patients with more pain are more dissatisfied with their care. As a result, some have concluded that little relationship exists between pain severity and patient satisfaction.

In light of conflicting studies, and because depression and pain commonly coexist and exacerbate one another in terms of various outcomes [21], we sought to better understand the relationship between depression and pain severity on satisfaction, a key care-quality indicator, in a large sample of outpatients with one or more common chronic medical conditions.

\section{METHODS}

\section{Data Source}

We analyzed cross-sectional data from the Medical Outcomes Study (MOS), a 4-year prospective observational study of adult outpatients conducted from 1986 to 1990. The original MOS was designed to examine the effects of specific characteristics of patients, providers, and healthcare systems on multiple outcomes, including health-related quality of life, patient satisfaction, healthservices use, and clinical end points at three study sites (Boston, Massachusetts; Chicago, Illinois; and Los Angeles, California) [22]. Telephone interviews were used to collect baseline data and outcomes at 12, 24, and 48 months followup. Within each system of care (health maintenance organizations, large multispecialty groups, and solo practices), a representative sample of general internists, family practitioners, endocrinologists, cardiologists, and psychiatrists/psychologists were recruited to participate. The sampling strategies employed in the MOS have been detailed previously [23]. For this article, we analyzed baseline data relevant to pain, depression, and patient satisfaction.

This analysis of MOS data was deemed exempt by the institutional review boards at Indiana University and the Richard L. Roudebush Department of Veterans Affairs (VA) Medical Center Research and Development Committee.

\section{Sample}

Briefly, patients were screened for one of five chronic illnesses or "tracer" conditions. These conditions were hypertension, congestive heart failure, myocardial infarction (recent or past), diabetes mellitus (type 1 or 2), and depression. More than 22,000 patients were initially screened. Completed data forms from physicians and patients were used to identify participants with hypertension, congestive heart failure, myocardial infarction, and diabetes.

Patients with depression were identified in a two-step screening procedure administered by telephone. In step 1, an 8-item depression scale that assessed intensity of symptoms over the past week and episodes of depressed mood over the past year was used [24]. In step 2, the depression section of the National Institute of Mental Health (NIMH) Diagnostic Interview Schedule (DIS) was administered to those who were positive for depression in step 1 [25]. A diagnosis of current depression was based on Diagnostic and Statistical Manual of Mental Disorders-Third Edition (DSM-III) criteria [26] and included both major depression and/or dysthymia. Patients with depressive symptoms that exceeded the cutoff screening score but did not satisfy the DSM-III definition for a current disorder were considered to have minor depression.

The study sample included 3,361 patients with at least one tracer condition (depression, hypertension, heart failure, diabetes, and/or myocardial infarction) and who completed a self-administered patient questionnaire by mail after enrollment [27-29].

\section{Patient Satisfaction Outcomes}

The primary outcomes were the seven subscale scores from the self-administered 50-item Patient Satisfaction Questionnaire-Third Edition (PSQ-III), adapted by Marshall et al. and used in the MOS [30]. The PSQ-III was designed to measure satisfaction with medical care in general as opposed to specific services, such as paincare services. Respondents were asked to rate their medical care, without reference to a specific visit or episode of care. PSQ-III subscales assess satisfaction in the following domains: (1) general satisfaction, (2) technical quality, (3) interpersonal manner, (4) communication, (5) access 
(to care) and convenience (availability of services), (6) financial aspects, and (7) time spent with doctor.

- General satisfaction (6 items): relates to patients' satisfaction with their overall care experience.

- Technical quality (10 items): assesses perceptions of provider's diagnosis and treatment skills (e.g., thoroughness, accuracy, and provision of the most effective treatment).

- Interpersonal manner (7 items): assesses the providerpatient interaction and provider's ability to listen, understand the patient's concerns, and demonstrate courtesy and respectfulness.

- Communication (5 items): relates to a provider's ability to communicate information about medical conditions and treatment options.

- Access and convenience (12 items): assesses whether medical care resources are readily available, ease of reaching the medical facility, waiting times, and whether continuity of care is maintained.

- Financial aspects (8 items): relates to any difficulty paying for medical care.

- Time spent with doctor (2 items): assesses whether time spent with the provider was viewed as sufficient.

The PSQ-III includes both factual and perceptual questions and statements related to the care patients most recently received (or were receiving). Item responses are coded from 1 to 5 , with 1 = "strongly agree" and $5=$ "strongly disagree." Questions are worded both favorably and unfavorably to provide a balanced distribution of scores that reduce the skewing common to other satisfaction measures and therefore aid interpretation [31]. Scoring of each subscale involves linearly combining all included items and results in a continuous score from 0 (least satisfied) to 100 (most satisfied). The PSQ-III's reliability and validity are based on its use in more than 2,000 patients followed longitudinally in the MOS [22]. Cronbach alpha coefficients for the seven scales have been estimated at 0.82 to 0.89 , and three approaches were used in the MOS to establish validity [32]: the PSQ-III has been shown to be reliable and well-validated and reflects general satisfaction as well as discrete dimensions of satisfaction with care.

\section{Independent Measures}

\section{Depression}

Depression was assessed by the NIMH DIS. The DIS is a highly structured diagnostic interview that identifies current psychiatric disorders according to DSM-III criteria [26]. Wells et al. demonstrated that telephone and face-to-face administration are equivalent in identifying lifetime depressive disorders [33]. For purposes of this study, depression status (minor or major) was dichotomized as either present or absent.

\section{Pain}

Pain was measured with the 36-item Short Form Bodily Pain (SF-36 BP) scale [28], a two-item scale that assesses pain severity and pain interference in the last 4 weeks. The SF-36 BP provides a composite score ranging from 0 (very severe pain and interference) to 100 (no pain and interference). We analyzed pain severity separately to address the individual contribution of this construct. We operationalized the pain severity item ("How much bodily pain have you had during the past 4 weeks? Have you had . . . ? (a) none, (b) very mild, (c) mild, (d) moderate, (e) severe, or (f) very severe") into four pain-severity classes of increasing intensity. The item responses were categorized as $1=$ "none" or "very mild," 2 = "mild," 3 = "moderate," 4 = "severe" or "very severe." We collapsed the responses into four classes to simplify data analysis and interpretation, a method we have reported previously [34].

Other factors included in our analyses that were potentially related to patient satisfaction were age; sex; race/ ethnicity (white, black, or other); education (in years); income; marital status (married or not); and diagnosis of congestive heart failure, myocardial infarction, and severe hypertension.

\section{Analysis}

Data were analyzed with Statistical Analysis Software, version 9.1 (SAS Institute Inc, Cary, North Carolina). A multivariate linear regression model was used to identify factors related to the seven subscales of patient satisfaction (general satisfaction, technical quality, interpersonal manner, communication, access and convenience, financial aspects, and time spent with doctor). We fit the model using generalized estimating equations (GEE), a methodology that has been used in previous studies [35-36], to adjust for correlated errors between the seven dependent measures, which in this analysis included the seven domains of satisfaction modeled simultaneously. The GEE method is an extension of the generalized linear model and has become an important method for analyzing correlation structures for longitudinal 
and clustered data [37]. Variables were retained in the multivariate model if $p<0.05$, by forward-elimination model selection. For independent variables with missing data, we imputed values using multiple imputation. We tested for interactions between all seven satisfaction domains and major or minor depression (present or not), pain severity, and patient age. Variables are said to interact if the effect of the explanatory variable (e.g., major depression) on the dependent variable (specific satisfaction domain) depends on the level of the explanatory variable. Interaction implies that the variables should be considered together and not separately.

\section{RESULTS}

Complete satisfaction data was for available for 95.6 percent $(n=3,213)$ of the patients in our sample. Patient characteristics, including demographics, prevalence of tracer and other medical conditions, and pain severity, are summarized in Table 1. The mean age of our sample was 54.3 years, with an average of 13.3 years of education; 61.9 percent of the sample was female, 78.9 percent was white, 58.5 percent was married, and 54.7 percent was employed full- or part-time. Tracer conditions (congestive heart failure, diabetes mellitus, hypertension, myocardial infarction, and depression) were common in this sample, which reflects the targeted recruitment strategy of the MOS for common medical problems. Hypertension was the most prevalent condition at 62.1 percent; 23.4 percent had minor depression and 15.0 percent had major depression. For the entire sample, pain was present in the majority (50.6\%) of patients. Overall, 19.7 percent had mild pain, 22.7 percent had moderate pain, and 8.2 percent had severe pain. Back (23.9\%), musculoskeletal problems (14.5\%), and osteoarthritis (6.3\%) were the most common pain problems reported.

Among patients with depression $(n=1,288)$, the prevalence of pain was $>80$ percent. Specifically, in those with major depression, only 17 percent reported no pain, whereas 41 percent had mild pain, 28 percent had moderate pain, and 14 percent had severe pain. Similar prevalence rates (15\% without pain and 48\%, 24\%, and $14 \%$ with mild, moderate, and severe pain, respectively) were seen in those with minor depression.

Table 2 summarizes the adjusted mean scores for the seven satisfaction domains or dependent measures in this analysis. These data demonstrate differences in general satisfaction as well as satisfaction with specific aspects of
Table 1.

Characteristics of patient sample. Data presented as $n$ (\%) unless otherwise noted.

\begin{tabular}{lc}
\hline \multicolumn{1}{c}{ Variable } & Value \\
\hline Demographics $(n=3,361)$ & \\
Age (yr) (mean \pm standard deviation [SD]) & $54.3 \pm 15.7$ \\
Female (\%) & 61.9 \\
Race/Ethnicity (\%) & \\
White & 78.9 \\
Black & 14.5 \\
Other & 6.6 \\
Married (\%) & 58.5 \\
Education (yr) (mean \pm SD) & $13.3 \pm 3.0$ \\
Employed (full- or part-time) (\%) & 54.7 \\
Tracer Conditions & $216(6.4)$ \\
Congestive Heart Failure & $629(18.7)$ \\
Diabetes Mellitus (type 1 or 2) & $2,089(62.1)$ \\
Hypertension & $322(9.6)$ \\
Myocardial Infarction & $785(23.4)$ \\
Minor Depression & $503(15.0)$ \\
Major Depression & \\
Other Medical Conditions & $803(23.9)$ \\
Back Problems & $216(6.4)$ \\
Cancer & $162(4.8)$ \\
Chronic Obstructive Pulmonary Disease & $488(14.5)$ \\
Musculoskeletal Problems & $213(6.3)$ \\
Osteoarthritis & \\
Pain Severity ( $n=3,215)$ & $264(8.2)$ \\
No Pain & \\
Mild & \\
Moderate & \\
Severe & \\
\hline \hline & \\
\hline
\end{tabular}

care, while analysis controlled for covariates such as demographics, major and minor depression, pain presence and severity, medical comorbidity, and interaction terms (e.g., major depression $\times$ each of the satisfaction domains).

The multivariate model found that satisfaction ratings in this sample of outpatients were highest in the areas of interpersonal manner (i.e., aspects of the patientprovider interaction) and communication (i.e., provider's ability to communicate with the patient) and lowest for financial aspects of care and time spent with the doctor.

Table 3 summarizes the independent variables and interactions between variables found to be statistically significant in the final multivariate model. As shown, increased age and diagnosis of congestive heart failure were associated with higher satisfaction scores. On the other hand, minor depression, major depression, and 
Table 2.

Adjusted Patient Satisfaction Questionnaire-Third Edition mean scores $(n=3,213)$.

\begin{tabular}{lc}
\hline Satisfaction Domain* & Mean \pm Standard Deviation \\
\hline General Satisfaction & $63.0 \pm 19.8$ \\
Technical Quality & $66.3 \pm 16.1$ \\
Interpersonal Manner & $71.2 \pm 26.1$ \\
Communication & $70.3 \pm 18.3$ \\
Access and Convenience & $70.3 \pm 15.1$ \\
Financial Aspects & $64.9 \pm 21.6$ \\
Time Spent with Doctor & $64.1 \pm 23.5$ \\
\hline
\end{tabular}

*Patient Satisfaction Questionnaire-Third Edition scores for each domain range from 0 (lowest satisfaction) to 100 (greatest satisfaction).

increasing pain severity were associated with lower satisfaction scores. Specifically, patients with minor or major depression had satisfaction scores almost 4 and 8 points lower, respectively, compared with patients without depression. Pain severity was associated with a 2.28point decrease in satisfaction for each increase in pain level. For example, patients with mild pain had, on average, $>2$ point decrease in satisfaction scores compared with those without pain. Furthermore, patients with severe pain had an approximately 7 point decrease in satisfaction scores compared with those without pain-just slightly less than patients with major depression. These data also show that the combination of depression and pain had additive negative effects on satisfaction. Estimated covariate effects for education, sex, race/ethnicity, marital status, income, myocardial infarction, diabetes mellitus, and severe hypertension were not statistically significant.

We observed significant interactions $(p<0.05)$ in our final regression model between minor or major depression and several of the seven satisfaction domains (Table 3). In other words, the association between depression and satisfaction differs depending on whether depression is present or not and what satisfaction domain is tested for interaction. For example, patients with major depression (relative to those without major depression) have higher satisfaction scores in the areas of technical quality (i.e., perceptions of providers' diagnosis and treatment skills) and access and convenience (i.e., availability of healthcare resources, ease of getting to medical facility, and waiting times), but lower scores for general satisfaction, financial aspects, and time spent with the doctor. These results are similar for minor and major depression. The interaction between depression and pain was not significant in the model.

\section{DISCUSSION}

This analysis of MOS data adds to the literature by demonstrating the high prevalence of pain (50.6\%) in patients with one or more common chronic medical conditions. Furthermore, pain prevalence was especially high $(>80 \%)$ in patients with depression in this sample. Both minor and major depression as well as pain severity strongly predicted lower satisfaction scores after analysis controlled for sociodemographics and medical comorbidity. This study extends our understanding of how depression and pain negatively affect patient satisfaction across different aspects of care, such as access to services, perceptions of technical ability of providers, and patient-provider interactions. Strengths of this study include analysis of data from the landmark MOS study, large sample size, rigorous analytic plan, and use of a comprehensive satisfaction measure that assessed general (overall) and specific satisfaction domains.

The frequent overlap between pain and depression has been previously documented. Some studies have demonstrated a high prevalence of pain in depressed patients in psychiatric or other specialty settings (e.g., pain clinics) [38-41]. Likewise, primary care studies have reported a pain prevalence as high as 69 percent in those with depression [34]. The fact that depressed patients in the MOS were sampled from psychiatric, specialty, and primary care settings and had coexisting medical conditions may account for the particularly high prevalence of pain.

Our findings are consistent with studies that show depression is associated with patient dissatisfaction [12-14]. To explain this association, Greenley et al. postulated four hypotheses: (1) general dissatisfaction, (2) negative reaction from provider, (3) needs assessment, and (4) patient attribution [12]. The general-dissatisfaction hypothesis states that those with depression are dissatisfied with life in general, which eventually translates into dissatisfaction with their medical care. The negative-reaction hypothesis states that healthcare providers "stigmatize" and react negatively toward those with depression. The needs-assessment hypothesis postulates that patients become dissatisfied when their depression or psychological needs are not acknowledged or addressed by providers, 
JRRD, Volume 44, Number 2, 2007

Table 3.

Predictors of patient satisfaction in Medical Outcomes Study sample. Multiple regression results with main effects and interactions.

\begin{tabular}{|c|c|c|}
\hline Variable & Estimate* $^{*}$ & Standard Error \\
\hline \multicolumn{3}{|l|}{ Independent Variable } \\
\hline Minor Depression & -3.61 & 0.32 \\
\hline Major Depression & -7.69 & 0.39 \\
\hline Congestive Heart Failure & 2.32 & 0.51 \\
\hline Age & 0.13 & 0.01 \\
\hline \multicolumn{3}{|l|}{ Minor Depression } \\
\hline Technical Quality & 0.86 & 1.10 \\
\hline Access and Convenience & 1.01 & 1.10 \\
\hline Financial Aspects & -3.37 & 1.14 \\
\hline Time with Doctor & -1.32 & 1.10 \\
\hline Access and Convenience & 2.78 & 1.16 \\
\hline Financial Aspects & -2.49 & 1.22 \\
\hline Time with Doctor & -2.02 & 1.16 \\
\hline
\end{tabular}

while the patient-attribution hypothesis states that patients who do not attribute at least some of their health problems/symptoms to depression are more dissatisfied with care. Of the four, modest support has been found for the "patient attribution" hypotheses in those psychologically distressed patients who do not admit emotional or personal problems and who tend to be more dissatisfied with healthcare services [12]. In addition, these patients tend to "downplay" the seriousness of their problems and do not routinely seek out professional help because of denial or avoidance, potentially delaying needed treatment.

Our study extends previous research on satisfaction outcomes by detailing how depression affects satisfaction with various aspects of healthcare encounters differently. Interaction testing revealed that major depression predicted higher satisfaction scores in the areas of perceived technical quality and access to healthcare resources, but lower scores for general satisfaction, financial aspects, and time spent with the doctor. Higher satisfaction in this setting may be explained by the fact that patients with depression are relatively frequent users of the healthcare system (e.g., frequent visits with their provider) and, in general, do not have problems accessing care. On the other hand, patients with depression may not be getting their psychological needs met and perceive being rushed in the average 15- to 20-minute primary care visit, which leads to dissatisfaction. Major depression has become the fourth leading cause of disability worldwide [42] and can also lead to unemployment. Multiple studies have shown that people who are unemployed, divorced, and impoverished have higher rates of depression. Fewer studies about the relationship between socioeconomic status and satisfaction ratings are available. However, in our initial model development, we tested the independent effects of income, education, and marital status on patient satisfaction. None of these variables was found to be significant and therefore was not included in the final model.

In contrast to our findings, several studies of hospitalized and postoperative patients have indicated high levels of satisfaction with care despite the presence of moderate-to-severe pain [17-19,43]. To explain this "paradox," Ward and Gordon hypothesized that higher levels of pain postoperatively are consistent with patient expectations. Patients expect to have pain after surgery, and thus, pain severity does not negatively affect satisfaction ratings [43]. On the other hand, experiencing more pain 
than expected or expecting minimal pain may lead to dissatisfaction with care [44-45]. Consistent with our results, several studies have found satisfaction ratings and level of pain to be inversely correlated [44,46-47]. One study reported that pain severity was unrelated to satisfaction, but outcomes, such as pain relief and improved function after pain treatment, predicted the satisfaction level [48].

Other correlates of patient satisfaction include interpersonal, process, and patient factors. Interpersonal factors, such as communicating to patients that managing their pain was "important" to healthcare team members [43] and showing concern for patients with pain [46], have been positively associated with satisfaction. Process factors, such as longer waiting times for pain clinic appointments or delayed telephone calls, may predict lower levels of satisfaction [48]. Patient-level factors, such as patient's perceptions of control over pain, are other possible correlates of satisfaction. For example, Pellino and Ward found that the perception of control over pain among postoperative orthopedic patients was more strongly associated with satisfaction than pain severity [49].

Reviews have established that concurrent depression and pain have a much greater impact than either disorder alone on multiple outcomes including duration/development of symptoms, health-related quality of life, disability, functional status, response to treatment, and healthservices use $[21,50]$. Patient satisfaction ratings have rarely been studied in patients with coexisting depression and pain. McCracken et al. examined the combined effect of depression and pain on patient satisfaction and found that depression predicts dissatisfaction with treatment in pain clinic patients [48]. In our study, we found an additive negative effect of both minor and major depression and pain on patient satisfaction.

Several limitations of our study deserve mention. First, the cross-sectional nature of our analyses limits causal inferences regarding the relationship between depression, pain, and patient satisfaction. Second, since the MOS included a select sample of patients who were insured, were involved in a lengthy and comprehensive study, and had a continuous relationship with a healthcare provider in three large U.S. cities, the findings from this study may not readily generalize to a broad spectrum of settings. Third, the original MOS data were collected between 16 and 20 years ago. Since then, several advances in depression screening and treatment have occurred that may affect the relationship between pain, depression, and satisfaction with care today. Fourth, we did not assess some known predictors of satisfaction, such as patients' trust in their provider and effectiveness of patient-provider communication.

\section{CONCLUSIONS}

In conclusion, pain is very common in this sample of outpatients with one or more chronic medical conditions. Depression and pain have a substantial and negative impact on patient satisfaction. Attention to patient satisfaction has benefits from healthcare plan and financial perspectives by increasing (or at least maintaining) enrollment. In addition, these findings may also have care-delivery implications, should dissatisfaction prove to be a marker for poorer quality of care. Future research should examine the specific reasons for dissatisfaction in patients with depression and pain and how these reasons relate to other clinical outcomes and quality indicators.

\section{ACKNOWLEDGMENTS}

We especially want to thank our colleague, Dr. Bernd Löwe, from the University of Heidelberg, Heidelberg, Germany, for his insightful editorial comments that assisted us in our preparation of this article.

All opinions expressed herein are those of the authors and do not in any way represent those of the VA.

This material was based on work supported by the VA, Veterans Health Administration, Health Services Research and Development Service, Research Career Development Award, and the NIMH (grant RO1 MH071268-01).

The authors have declared that no competing interests exist.

\section{REFERENCES}

1. Chassin MR, Galvin RW. The urgent need to improve health care quality. Institute of Medicine National Roundtable on Health Care Quality. JAMA. 1998;280(11):10001005. [PMID: 9749483]

2. McGlynn EA, Asch SM, Adams J, Keesey J, Hicks J, DeCristofaro A, Kerr EA. The quality of health care delivered to adults in the United States. N Engl J Med. 2003;348(26): 2635-45. [PMID: 12826639] 
3. Cleary PD, McNeil BJ. Patient satisfaction as an indicator of quality care. Inquiry. 1988;25(1):25-36. [PMID: 2966123]

4. Kane RL, Maciejewski M, Finch M. The relationship of patient satisfaction with care and clinical outcomes. Med Care. 1997;35(7):714-30. [PMID: 9219498]

5. Health Services Research Group. A guide to direct measures of patient satisfaction in clinical practice. Can Med Assoc J. 1992;146(10):1727-31.

6. Ley P. Satisfaction, compliance and communication. Br J Clin Psychol. 1982;21(Pt 4):241-54. [PMID: 7171877]

7. Wartman SA, Morlock LL, Malitz FE, Palm EA. Patient understanding and satisfaction as predictors of compliance. Med Care. 1983;21(9):886-91. [PMID: 6621118]

8. Sherbourne CD, Hays RD, Ordway L, DiMatteo MR, Kravitz RL. Antecedents of adherence to medical recommendations: Results from the Medical Outcomes Study. J Behav Med. 1992;15(5):447-68. [PMID: 1447757]

9. Penchansky R, Macnee C. Initiation of medical malpractice suits: A conceptualization and test. Med Care. 1994;32(8): 813-31. [PMID: 8057697]

10. Marquis MS, Davies AR, Ware JE Jr. Patient satisfaction and change in medical care provider: A longitudinal study. Med Care. 1983;21(8):821-29. [PMID: 6888031]

11. Ware JE Jr, Davies AR. Behavioral consequences of consumer dissatisfaction with medical care. Eval Program Plann. 1983;6(3-4):291-97. [PMID: 10267257]

12. Greenley JR, Young TB, Schoenherr RA. Psychological distress and patient satisfaction. Med Care. 1982;20(4): 373-85. [PMID: 7078294]

13. Linn LS, Greenfield S. Patient suffering and patient satisfaction among the chronically ill. Med Care. 1982;20(4): 425-31. [PMID: 7078298]

14. Hoff RA, Rosenheck RA, Meterko M, Wilson NJ. Mental illness as a predictor of satisfaction with inpatient care at Veterans Affairs hospitals. Psychiatr Serv. 1999;50(5):680-85. [PMID: 10332906]

15. Meredith LS, Orlando M, Humphrey N, Camp P, Sherbourne $\mathrm{CD}$. Are better ratings of the patient-provider relationship associated with higher quality care for depression? Med Care. 2001;39(4):349-60. [PMID: 11329522]

16. Price JR, Blake F. Chronic pelvic pain: The assessment as therapy. J Psychosom Res. 1999;46(1):7-14.

[PMID: 10088977]

17. Ward SE, Gordon D. Application of the American Pain Society quality assurance standards. Pain. 1994;56(3):299306. [PMID: 8022623]

18. Miaskowski C, Nichols R, Brody R, Synold T. Assessment of patient satisfaction utilizing the American Pain Society's Quality Assurance Standards on acute and cancer-related pain. J Pain Symptom Manage. 1994;9(1):5-11. [PMID: 8169462$]$
19. Donovan BD. Patient attitudes to postoperative pain relief. Anaesth Intensive Care. 1983;11(2):125-29.

[PMID: 6869774]

20. Dawson R, Spross JA, Jablonski ES, Hoyer DR, Sellers DE, Solomon MZ. Probing the paradox of patients' satisfaction with inadequate pain management. J Pain Symptom Manage. 2002;23(3):211-20. [PMID: 11888719]

21. Bair MJ, Robinson RL, Katon W, Kroenke K. Depression and pain comorbidity: A literature review. Arch Intern Med. 2003;163(20):2433-45. [PMID: 14609780]

22. Tarlov AR, Ware JE Jr, Greenfield S, Nelson EC, Perrin E, Zubkoff M. The Medical Outcomes Study. An application of methods for monitoring the results of medical care. JAMA. 1989;262(7):925-30. [PMID: 2754793]

23. Rogers WH, McGlynn EA, Berry SH, Nelson EC, Perrin E, Zubkoff M, Greenfield S, Wells KB, Stewart AL, Arnold SB, Ware JE Jr. Methods of sampling. In: Stewart AL, Ware JE Jr, editors. Measuring functional status and wellbeing: The Medical Outcomes Study approach. Durham (NC): Duke University Press; 1992. p. 27-48.

24. Burnam MA, Wells KB, Leake B, Landsverk J. Development of a brief screening instrument for detecting depressive disorders. Med Care. 1988;26(8):775-89. [PMID: 3398606]

25. Robins LN, Helzer JE, Croughan J, Ratcliff KS. National Institute of Mental Health Diagnostic Interview Schedule. Its history, characteristics, and validity. Arch Gen Psychiatry. 1981;38(4):381-89. [PMID: 6260053]

26. American Psychiatric Association. Diagnostic and statistical manual of mental disorders-Third edition. Washington (DC): American Psychiatric Association; 1980.

27. Haley SM, McHorney CA, Ware JE Jr. Evaluation of the MOS SF-36 physical functioning scale (PF-10): I. Unidimensionality and reproducibility of the Rasch item scale. J Clin Epidemiol. 1994;47(6):671-84. [PMID: 7722580]

28. McHorney CA, Ware JE Jr, Raczek AE. The MOS 36-Item Short-Form Health Survey (SF-36): II. Psychometric and clinical tests of validity in measuring physical and mental health constructs. Med Care. 1993;31(3):247-63. [PMID: 8450681]

29. McHorney CA, Ware JE Jr, Lu JF, Sherbourne CD. The MOS 36-item Short-Form Health Survey (SF-36): III. Tests of data quality, scaling assumptions, and reliability across diverse patient groups. Med Care. 1994;32(1):40-66. [PMID: 8277801]

30. Marshall GN, Hays RD, Sherbourne CD, Wells KB. The structure of patient satisfaction with outpatient medical care. Psychol Assess. 1993;5(4):477-83.

31. Ware JE Jr, Snyder N, Wright WR. Development and validation of scales to measure patient satisfaction with medical care services. Vol. I, Part B: Results regarding scales constructed from the Patient Satisfaction Questionnaire and 
measures of other health care perceptions. Springfield (MA): National Technical Information Service; 1976.

32. Teague GB. Patient perceptions of care measures. Handbook of psychiatric measures. Washington (DC): American Psychiatric Association; 2000. p. 179-82.

33. Wells KB, Burnam MA, Leake B, Robins LN. Agreement between face-to-face and telephone-administered versions of the depression section of the NIMH Diagnostic Interview Schedule. J Psychiatr Res. 1988;22(3):207-20. [PMID: 3225790]

34. Bair MJ, Robinson RL, Eckert GJ, Stang PE, Croghan TW, Kroenke K. Impact of pain on depression treatment response in primary care. Psychosom Med. 2004;66(1):1722. [PMID: 14747633]

35. Breslau N, Chilcoat HD, Susser ES, Matte T, Liang KY, Peterson EL. Stability and change in children's intelligence quotient scores: A comparison of two socioeconomically disparate communities. Am J Epidemiol. 2001;154(8):71117. [PMID: 11590083

36. Flach SD, Diekema DJ, Yankey JW, BootsMiller BJ, Vaughn TE, Ernst EJ, Ward MM, Doebbeling BN. Variation in the use of procedures to monitor antimicrobial resistance in U.S. hospitals. Infect Control Hosp Epidemiol. 2005;26(1):31-38. [PMID: 15693406]

37. Hardin JW, Hilbe J. Generalized estimating equations. Boca Raton (FL): Chapman \& Hall/CRC Press; 2003.

38. Merskey H, Spear FG. The concept of pain. J Psychosom Res. 1967;11(1):59-67. [PMID: 6049032]

39. Delaplaine R, Ifabumuyi OI, Merskey H, Zarfas J. Significance of pain in psychiatric hospital patients. Pain. 1978;4(4): 361-66. [PMID: 643300]

40. Diamond S. Depressive headaches. Headache. 1964;4:25559. [PMID: 14238837]

41. Von Knorring L, Perris C, Eisemann M, Eriksson U, Perris H. Pain as a symptom in depressive disorders. I. Relationship to diagnostic subgroup and depressive symptomatology. Pain. 1983;15:19-26.

42. Murray CJ, Lopez AD. Alternative projections of mortality and disability by cause 1990-2020: Global Burden of Dis- ease Study. Lancet. 1997;349(9064):1498-1504.

[PMID: 9167458]

43. Ward SE, Gordon DB. Patient satisfaction and pain severity as outcomes in pain management: A longitudinal view of one setting's experience. J Pain Symptom Manage. 1996;11(4):242-51. [PMID: 8869459]

44. Carroll KC, Atkins PJ, Herold GR, Mlcek CA, Shively M, Clopton P, Glaser DN. Pain assessment and management in critically ill postoperative and trauma patients: A multisite study. Am J Crit Care. 1999;8(2):105-17.

[PMID: 10071701]

45. Thomas T, Robinson C, Champion D, McKell M, Pell M. Prediction and assessment of the severity of post-operative pain and of satisfaction with management. Pain. 1998; 75(2-3):177-85. [PMID: 9583753]

46. Jamison RN, Ross MJ, Hoopman P, Griffin F, Levy J, Daly M, Schaffer JL. Assessment of postoperative pain management: Patient satisfaction and perceived helpfulness. Clin J Pain. 1997;13(3):229-36. [PMID: 9303255]

47. McNeill JA, Sherwood GD, Starck PL, Thompson CJ. Assessing clinical outcomes: Patient satisfaction with pain management. J Pain Symptom Manage. 1998;16(1):29-40. [PMID: 9707655]

48. McCracken LM, Klock PA, Mingay DJ, Asbury JK, Sinclair DM. Assessment of satisfaction with treatment for chronic pain. J Pain Symptom Manage. 1997;14(5):292-99. [PMID: 9392923]

49. Pellino TA, Ward SE. Perceived control mediates the relationship between pain severity and patient satisfaction. J Pain Symptom Manage. 1998;15(2):110-16. [PMID: 9494309]

50. Gallagher RM, Verma S. Managing pain and comorbid depression: A public health challenge. Semin Clin Neuropsychiatry. 1999;4(3):203-20. [PMID: 10498788]

Submitted for publication June 1, 2006. Accepted in revised form October 6, 2006. 